\title{
Comparison between ultrasound-guided TIVAD via the right innominate vein and the right internal jugular vein approach
}

\author{
Xingwei Sun ${ }^{1+}$, Xuming Bai ${ }^{1+}$, Jiaofeng Shen ${ }^{2}$, Ziyang $\mathrm{Yu}^{3}$, Zhixiang Zhuang ${ }^{2^{*}}$ and Yong Jin $^{1^{*}}$
}

\begin{abstract}
Background: To compare the efficacy and safety of right internal jugular vein (IJV) approach and right innominate vein (INV) approach for US-guided totally implantable venous access devices (TIVADs), and to explore the advantages and disadvantages of the two approaches.

Methods: Six hundred and nineteen adult patients had long-term infusion and chemotherapy needs and inconvenience of peripheral venous infusion. Right INV approach was used to implant 339 cases of TIVADs, and right IJV approach was used to implant 280 cases of TIVADs. The success rate of one-time catheterization and the incidence of complications in the two groups were retrospectively analyzed.

Results: All patients were successfully implanted in TIVAD. The success rates of one-time puncture in INV group and IJV approach group were 98.53\% (334/339) and 95.36\% (267/280), respectively. There was significant difference between the two groups $(P=0.020)$. The incidence of perioperative complications and long-term complications in the right INV group were 1.18\% (4/339) and 3.54\% (12/339), respectively, while those in the right IJV group were $1.43 \%$ (4280) and 3.93\% (11280). There was no significant difference in the incidence of perioperative or long-term complications between the two groups $(P=0.785, P=0.799$, respectively).

Conclusions: US-guided TIVADs via the right INV approach and the right IJV approach are both safe and reliable. The right INV approach improves the one-time puncture success rate, as long as the technique is properly operated, serious complications rarely occur.
\end{abstract}

Keywords: Totally implantable venous access device, Innominate vein, Internal jugular vein, US-guided, Cancer

\section{Background}

The application of a totally implantable venous access device (TIVAD) is regarded as a leap-forward development of infusion technology, and it significantly reduces the risk of drug infusions, especially chemotherapeutic drug infusions [1]. TIVAD has been widely used in clinical application, which is superior to other long-term intravenous infusion pathways and is the best choice for cancer patients [2].

\footnotetext{
* Correspondence: 2104184578@qq.com; 578898234@qq.com

${ }^{+}$Xingwei Sun and Xuming Bai contributed equally to this work.

${ }^{2}$ Department of Oncology, The Second Affiliated Hospital of Soochow

University, Suzhou 215004, Jiangsu, China

${ }^{1}$ Department of Intervention, The Second Affiliated Hospital of Soochow

University, Suzhou 215004, Jiangsu, China

Full list of author information is available at the end of the article
}

In 1982, Niederhuber et al. [3] first placed TIVADs via the cephalic vein through surgical techniques. Nowadays, internal jugular vein (IJV) approach has become the most commonly used approach in clinical application because of its high success rate and low complications $[4,5]$.

In recently, with the continuous development of ultrasound (US) technology, the INV approach is gradually being considered and applied in clinical practice [6-8]. However, the reports of US-guided INV approach for TIVADs implantation in adult patients are limited [9].

In the previous research, we introduced the safety and feasibility of US-guided TIVADs via the right INV approach [10,11]. In this study, a total of 619 cases managed by US-guided TIVADs through the right INV or

(C) The Author(s). 2019 Open Access This article is distributed under the terms of the Creative Commons Attribution 4.0 International License (http://creativecommons.org/licenses/by/4.0/), which permits unrestricted use, distribution, and 
right IJV approach in our department were retrospectively compared and analyzed consecutively.

\section{Methods}

This study was approved by the Ethics Committee, and written informed consent was obtained from all the cases. The study cohort included adult patients receiving US-guided TIVADs through the right INV or right IJV approach from January 2016 to January 2018.

For the purposes of the present study, the success rate of operation, time of operation, success rate for the onetime puncture, catheterization length, and intraoperative and postoperative complications were recorded.

Clinical data were acquired from the operation and nursing records.

\section{Materials}

BardPort $(8,806,061,6 F$; UT, USA) and a LOGIQe ultrasound device (General Electric, Fairfield, CT) was used in all cases.

\section{Methods}

Sterile procedures were strictly followed during the surgery. The operation was performed by two experienced interventional physicians for our team.

The right INV TIVADs was performed as follows:

1. The patient is in a supine position with the head turned to the left。

2. The scope of disinfection should be more than 15 $\mathrm{cm}$ above the intended pipe and TIVAD site, and sterile sheet should be laid.

3. The high-frequency ultrasound probe runs down the right IJV to the sternoclavicular joint to get good view of the right INV. Local anesthesia was performed at the puncture site with $1 \%$ lidocaine. After successful puncture with in-plan technique (Fig. 1), it enters the guide wire, sheath, and catheter sequentially.

4. Skin incision was made at the ipsilateral subclavian $2-3 \mathrm{~cm}$, subcutaneous tissue was bluntly separated, and appropriate size pocket was made.

5. Using the subcutaneous tunnel needle, the catheter was subcutaneously introduced into the pocket from the puncture site. The tip of catheter was located at the junction of superior vena cava and right atrium under fluoroscopy. (Figure. 2).

6. Cut off the catheter and connect the catheter to the port. After local hemostasis, incisions were sutured and X-ray images of TIVAD were retained (Fig. 3).

\section{Maintenance of TIVADs}

The maintenance and management of the infusion port were performed by specialized nurses, and 10-ml

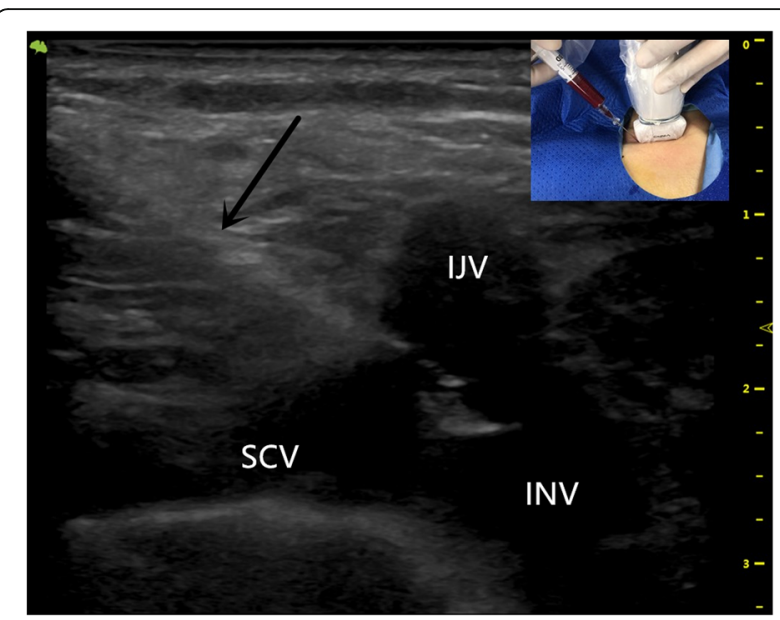

Fig. 1 Ultrasound-guided successful puncture of right INV with inserting needle (black arrow). INV longitudinal view, in-plane approach. INV indicates innominate vein; IJV indicates internal jugular vein; SCV indicates the subclavian vein

flushing tube of 50-100iu / $\mathrm{ml}$ heparin saline was used, not more than once in every 28 days.

\section{Data collection}

Success rate of the one-time puncture: the one-time is considered to be successful if the intraoperative puncture needle enters the INV or IJV and successfully enters the guidewire without a secondary puncture of skin.

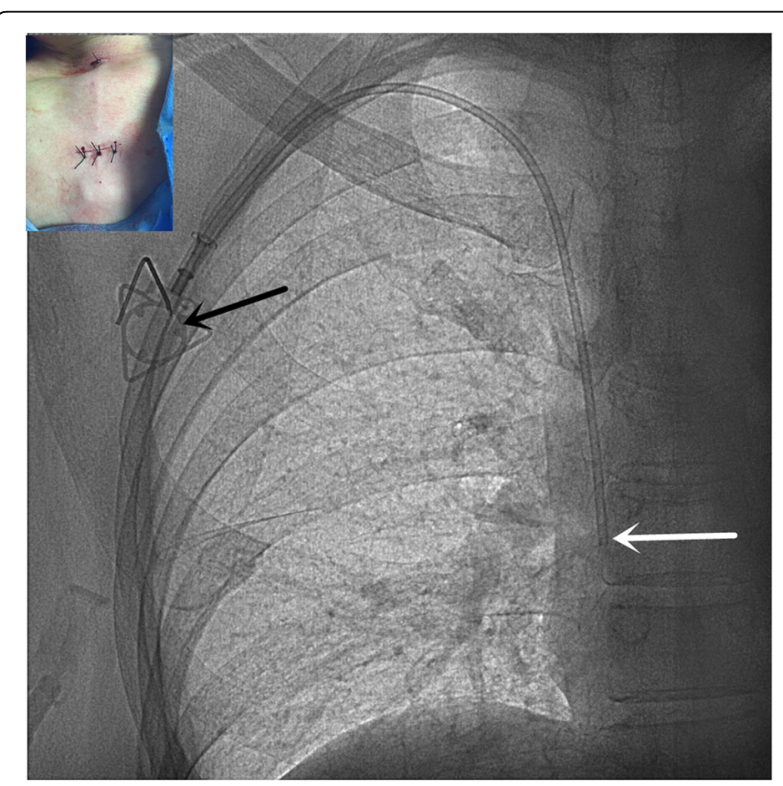

Fig. 2 The catheter crosses over the clavicle and enters the superior vena cava via the right INV. The port (black arrow) is located on the right chest wall, and the tip of the catheter (white arrow) is located at the junction of the superior vena cava and the right atrium 


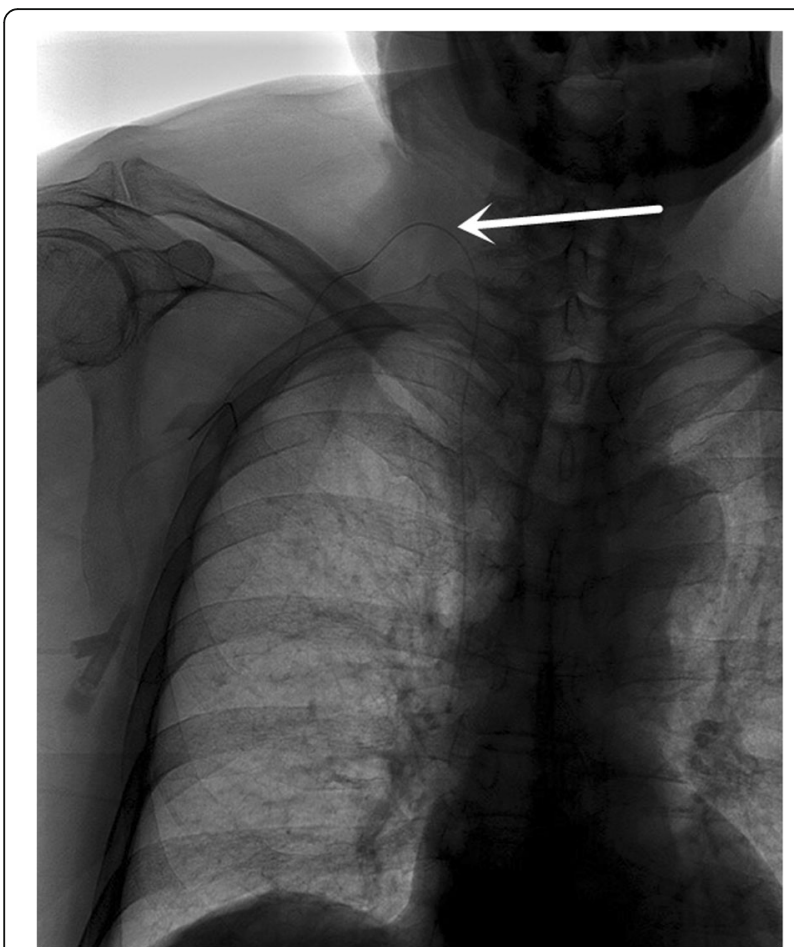

Fig. 3 TIVAD is implanted via the right IJV. The catheter crosses the clavicle and reversed into the right IJV. The white arrow indicates the angle at which the catheter folds

Perioperative complications: arterial puncture, pneumothorax, hemothorax, local hematoma formation, incision infection.

Postoperative complications: complications occurred two weeks after implantation, including thrombosis, fibrinolysis, pinch-off Syndrome, catheter malposition, catheter rupture, catheter-associated infection, port inversion, local skin rupture.

\section{Statistical analysis}

SPSS19.0 statistical software was used to statistically analyze the surgical details and postoperative complications of the two groups. The measurement data were represented by Mean $\pm \mathrm{SD}$, and T test was used for comparison between the two groups. The ratio of counting data indicated that chi-square test was used for the comparison between the two groups. $P<0.05$ was considered statistically significant.

\section{Results}

The general data between the two groups are summarized in Table 1. There was no statistical difference between the two groups in gender, age, height and weight.

Details of TIVADs procedure are summarized in Table 2. All patients underwent successful surgery. The success rate of one-time puncture in the right INV group was 334 (98.53\%) and that in the right IJV group was 267 (95.36\%). There was significant difference between the two groups $(P=0.020)$.

All 619 patients in this study were successfully implanted in TIVADs. The depth of catheterization (from the puncture point to the tip of the catheter) was $11-16 \mathrm{~cm}$. The mean length of catheter insertion was $19.64 \pm 4.37 \mathrm{~cm}$ (range of $16-21 \mathrm{~cm}$ ) in the right INV group and $23.47 \pm 6.31 \mathrm{~cm}$ (range of $19-26 \mathrm{~cm}$ ) in the right IJV group, and the difference was statistically significant $(P<0.01)$.

Perioperative complications were observed in 4 cases ( 2 artery puncture, 1 local hematoma and 1 pneumothorax) in the right INV group and 4 cases (3 artery puncture and 1 pneumothorax) in the right IJV group (Table 3). There were no hemopneumothorax and lymphatic duct injury in both groups. Perioperative complications rate did not have any significant difference (1.18\% vs $1.43 \%, P=0.785)$. None of these complications

Table 1 patient's characteristics

\begin{tabular}{|c|c|c|c|c|}
\hline & Overall $(N=619)$ & INV(N=339) & IJV(N = 280) & $P$ value \\
\hline Age (years) & $52.57 \pm 14.63$ & $54.75 \pm 14.62$ & $51.20 \pm 11.53$ & 0.812 \\
\hline Male / Female & $242 / 377$ & $128 / 211$ & $114 / 166$ & 0.453 \\
\hline Height (cm) & $165.43 \pm 12.37$ & $165.14 \pm 10.49$ & $167.10 \pm 13.04$ & 0.980 \\
\hline Weight (kg) & $56.64 \pm 14.12$ & $55.03 \pm 12.05$ & $58.66 \pm 9.19$ & 0.905 \\
\hline Body Mass Index & $19.64 \pm 3.69$ & $20.03 \pm 4.11$ & $19.20 \pm 3.15$ & 0.763 \\
\hline Prothrombin Time (seconds) & $13.23 \pm 3.52$ & $12.23 \pm 3.18$ & $14.45 \pm 2.29$ & 0.041 \\
\hline Activated Partial Thromboplastin Time (seconds) & $42.18 \pm 10.01$ & $41.20 \pm 7.12$ & $43.34 \pm 9.01$ & 0.670 \\
\hline Breast cancer (\%) & $256(41.36)$ & $141(35.34)$ & $115(35.71)$ & 0.896 \\
\hline Liver cancer (\%) & $154(24.88)$ & $86(25.39)$ & $68(24.29)$ & 0.756 \\
\hline Lung cancer (\%) & $128(20.68)$ & 75 (22.12) & 53 (18.93) & 0.329 \\
\hline Gastric cancer (\%) & 67 (10.82) & $30(8.85)$ & $37(13.21)$ & 0.082 \\
\hline Rectal cancer (\%) & $15(2.42)$ & $7(2.06)$ & $8(2.86)$ & 0.523 \\
\hline
\end{tabular}


Table 2 Showing details of TIVADs procedure and insertion duration

\begin{tabular}{lllll}
\hline & Overall $(N=619)$ & INV $(N=339)$ & IJV $(N=280)$ & $P$ value \\
\hline Success rate of one-time attempt $(N)$ & $97.09 \%(601)$ & $98.53 \%(334)$ & $95.36 \%(267)$ & 0.020 \\
Operation time (minutes) & $29.24 \pm 6.37$ & $28.15 \pm 5.97$ & $30.92 \pm 6.26$ & 0.303 \\
Length of catheter introduction $(\mathrm{cm})$ & $21.39 \pm 6.17$ & $19.64 \pm 4.37$ & $23.47 \pm 6.31$ & $<0.01$ \\
Port-carrying time (days) & $295.23 \pm 36.19$ & $312.09 \pm 48.10$ & $278.51 \pm 35.85$ & 0.039 \\
\hline
\end{tabular}

required any specific intervention except compression of the puncture site. The complete cannulation procedure was then repeated or changed the puncture site successfully.

The Port-carrying time in the right INV group and IJV group was $(312.09 \pm 48.10)$ days and $(278.51 \pm 35.85)$ days, respectively, with significant difference $(P=0.039)$.

Post-procedure complications happened in 12 patients in the INV group (poor healing of the incision in 1case, thrombosis in 1 case, catheter-related infection in 4 cases, fibrin sheath formation in 6 cases) and 11 patients in the IJV group (catheter-related infection in 2 cases, thrombosis in 2 cases, fibrin sheath formation in 4 cases, catheter malposition in 2 cases, and catheter fracture in 1 cases). Differences between groups about postoperative complications rate were not significant (3.54\% vs $3.93 \%, P=0.799$ ) (Table 3 ).

\section{Discussion}

This is the first study on a large sample comparing inplane US-guided supraclavicular right INV approach with right IJV approach for TIVADs in adults. Our main finding is that the INV technique had a significantly higher first-attempt success rate compared with IJV, and INV approach had lower perioperative and postoperative complications, although the differences between groups about complication rates were not significant. US-guided TIVADs via the right INV approach and the right IJV approach are both safe and reliable.
The methods of TIVADs implantation mainly include venous cutdown and venous puncture [12]. At present, percutaneous puncture for TIVADs implantation via IJV and SCV are the most widely used [4]. However, the IJV and SCV may not be the best option for many clinical situations.

TIVADs via IJV approach has a high puncture point and a large folding angle of the catheter (Fig. 3). This may lead to reduction of comfort, unattractive appearance and even lead to discount and rupture of the catheter [13-15]. The SCV approach is more convenient and comfortable than IJV, but SCV approach has the possibility of occurrence of pinch-off syndrome (POS), which is the main cause of catheter rupture [16].

Cephalic vein cut-down technique has been used for more than 30 years [5]. According to the previous studies, in comparison with the SCV approach, the incidence of complications of cephalic vein approach using surgical techniques for TIVAD is lower, and it is considered superior to the SCV approach [17-19]. KOKETSU et al. $[20,21]$ also believe that TIVAD can provide safe and feasible infusion channels for patients through cephalic vein, which is worthy of promotion and application. However, surgical techniques for TIVAD also have the disadvantages of long operation time, low success rate, and great trauma.

The IJV merges with the SCV behind the sternoclavicular joint to form the INV, the bilateral INVs converge to form the superior vena cava (SVC). We know that the

Table 3 Incidence of intraoperative and postoperative complications and processing measures $(N=619)$

\begin{tabular}{|c|c|c|c|c|}
\hline Complications & INV(N=339) & $I J V(N=280)$ & $P$ value & Intervention \\
\hline Artery puncture (\%) & $2(0.59)$ & $3(1.07)$ & & Self-limiting \\
\hline Local hematoma (\%) & $1(0.29)$ & 0 & & Compression \\
\hline Pneumothorax (\%) & $1(0.29)$ & $1(0.36)$ & & Self-limiting \\
\hline All preoperative complications (\%) & $4(1.18)$ & $4(1.43)$ & 0.785 & \\
\hline Poor healing of the incision(\%) & $1(0.29)$ & 0 & & Secondary suture \\
\hline Catheter-related infection (\%) & $4(1.18)$ & $2(0.71)$ & & Antibiotics, catheter removal \\
\hline Thrombosis (\%) & $1(0.29)$ & $2(0.71)$ & & Anticoagulation, catheter removal \\
\hline Fibrous sheath (\%) & $6(1.77)$ & $4(1.43)$ & & Thrombolysis Catheter removal \\
\hline Catheter fracture (\%) & 0 & $1(0.36)$ & & Catheter removal \\
\hline Catheter malposition (\%) & 0 & $2(0.71)$ & & Catheter removal \\
\hline All Postoperative complications (\%) & $12(3.54)$ & $11(3.93)$ & 0.799 & \\
\hline
\end{tabular}


INV is relatively fixed and has a larger diameter than the IJV and SCV, this provides the possibility of US-guided puncture of INV safely and effectively.

With the development of ultrasound technology, ultrasound-guided INV catheterization has been gradually applied in central vena catheterization (CVC) for almost 10 years, and many studies have confirmed its safety and effectiveness [6, 7, 9]. Early studies about INV catheterization were mainly focused on catheterization for neonates, possibly because of the small diameter of IJV in newborns than the adults and is more difficult to puncture; therefore, the INV approach was adopted.

Studies have shown that the success rate of left INV catheterization in infants and newborns is higher than that in right $[22,23]$. However, in adults, the left INV is deeper and more variable than the right, and it is difficult to identify the thoracic duct by ultrasound [11].

In this study, we chosed to puncture the right INV to avoid lymphatic leakage caused by thoracic duct injury, as reported in our previous study $[10,11]$. But in Beccaria's study [9], 78 patients with left INV catheterization did not have thoracic duct injury. Another study showed that left INV catheterization was safe and feasible in children [24]. Further studies are required to confirm the safety and feasibility of left INV approach of TIVADs for adult patients.

In this study, the success rate of one-time puncture in the right INV group was slightly higher than that in the right IJV group $(98.64 \%$ vs $95.34 \%, P=0.020)$ (Table 2). This was related to many anatomical advantages of right INV, such as thin subcutaneous tissue, large diameter and clear ultrasound display.

The success rate of the first puncture is related to the personal experience, besides, the ectopy of guidewire during puncture is also an important factor for the reduction of the rate of the first puncture of the internal jugular vein. In the right IJV group, the first puncture failed in 9 cases, among which 4 cases were confirmed to enter the ipsilateral SCV by DSA, and the guide wire was successfully adjusted. In the right INV group, there was no guide wire ectopy during puncture due to anatomical factor: Y-shaped anatomical morphology of IJV, SCV, and INV [6].

The success rate of the first puncture of INV reported in this study was higher than that of Beccaria et al. [9] $(90.18 \%, 257 / 285)$, which might be related to the left INV approach used in Beccaria's study.

Perioperative complications were mainly related to mechanical injury of central vein puncture. In this study, intraoperative complications rate in the right INV group was lower than that of IJV group although the differences were not statistically significant $(1.18 \%$ vs $1.43 \%$, $P>0.05$ ) (Table 3).
Perioperative complications were observed in 4 cases in the right INV group and in 3 casesin the right IJV group. The miss punctured artery was identified as right subclavical artery (SCA) or right common carotid artery (CCA) by ultrasound, and two patients were diagnosed as the small amount of pneumothorax by fluoroscopy during the operation. These self-limiting complications were not treated except for puncture site compression. The complete cannulation procedure was then repeated or changed the puncture site successfully.

The port-carrying time was mainly affected by the subjective factors of the patients. By the end of this study, 209 patients had their TIVADs removed autonomously or unplanned, among which $84.67 \%(177 / 209)$ of the patients thought that there was no need to use the infusion port in about 1 year. In addition, 5\% (14/280) of patients in the right IJV group were admitted for the removal of TIVADs due to local foreign body sensation or neck discomfort, while this condition was $2.06 \%(7 / 339)$ in the INV group.

The overall incidence of postoperative complications in the study was $3.72 \%(23 / 619)$ (Table 3$)$, which was consistent with that reported in most other studies [25, 26]. Postoperative complication rate of the right INV group was $3.54 \%(12 / 339)$, which was lower than that of the right IJV group $(3.93 \%, 11 / 280)$, although the differences were not statistically significant $(P=0.799)$.

Postoperative complications mainly included poor healing of the incision, catheter-related infection, thrombosis, fibrin sheath formation, catheter malposition, and catheter fracture, and most of these lead to an unplanned remove after the failure of processing measures (Table 3).

It is worth noting that there is no catheter malposition or catheter rupture in the right INV group, and the mechanism for the low incidence of catheter malposition or catheter rupture are still unclear.

Compared with JIV approach, the INV approach has the advantages of low mobility, smooth catheter shape, and it avoid POS with supraclavicular approach, these are important factors that reduce catheter malposition or fracture of the catheter [27-29]. In addition, Yshaped anatomical morphology of IJV, SCV, and INV is also a very important factor of INV approach to reduce catheter malposition.

The findings of our study have led to changes in our daily clinical practice. As a result of the high success rate of puncture, low rate of complications with right INV, we now prefer the right INV to IJV for TIVADs.

Considering its anatomical characteristics, we avoid the right INV in some conditions. Considering the need for surgery and radiotherapy, we do not allow patients with right breast cancer. Patients with not controlled local infection in the port area or the acute infection is 
not controlled effectively was not allowed. The catheter crosses the clavicle, and the emaciated patients are more likely to expose the catheter. The presence of coagulopathy should be considered as a relative contraindication.

Although this is a large sample comparison study with 619 enrolled patients, the study has certain limitations. First, this study was a retrospective review and some data were not accessible. Second, our incidence of postoperative complications might not be accurate, as we might have missed some TIVADs inserted at our hospital but removed in other institutions. Third, it was a monocentric study and all the TIVADs enrolled were of right INV approach or right IJV approach, the data of TIVADs with left INV approach are lacking, which may provide the further reference for clinicians. According to 2014 statistics, there were more than 400,000 cases of infusion port implantation in the United States, and about 477,300 cases of tumor were diagnosed in Germany every year, among which 125,790 cases chose TIVADs for chemotherapy [18]. At present, the clinical application of TIVAD is increasingly extensive, which is obviously better than other long-term intravenous infusion pathways and is the best choice for tumor patients, however, there are still many problems to be solved [30, 31].

\section{Conclusions}

US-guided TIVADs via the right INV approach and the right IJV approach are both safe and reliable. There is a clear need for prospective and well-organized studies to confirm the feasibility and safety of the ultrasoundguided INV approach (both right and left) for TIVADs. It may stimulate future research in this area greatly.

\section{Abbreviations}

CCA: Common carotid artery; CVC: Central vena catheterization; IJV: Internal jugular vein; INV: Innominate Vein; POS: Pinch-off syndrome; SCA: Subclavian artery; SCV: Subclavian vein; TIVAD: Totally implantable venous access device

\section{Acknowledgements}

Not applicable.

\section{Authors' contributions}

$X S$ and $X B$ proposed the study and wrote the first draft. J $S$ and $Z Y$ analyzed the data. $Z Z$ and $Y J$ contributed to the design of the study. All authors have read and approved the manuscript.

\section{Funding}

The study was funded by Pre-research Project of National Natural Science Foundation of China (SDFEYGJ1801) in the design of the study and collection, analysis, and interpretation of data.

\section{Availability of data and materials}

The datasets during the current study are available from the corresponding author on reasonable request.

\section{Ethics approval and consent to participate}

This study was approved by the Ethics Committee of the Second Affiliated Hospital of Soochow University, and written informed consent from all patients was available.
Consent for publication

Not Applicable.

\section{Competing interests}

All authors declare that they have no conflicts of interest.

\section{Author details}

'Department of Intervention, The Second Affiliated Hospital of Soochow University, Suzhou 215004, Jiangsu, China. ${ }^{2}$ Department of Oncology, The Second Affiliated Hospital of Soochow University, Suzhou 215004, Jiangsu, China. ${ }^{3}$ Department of Ultrasound, The Second Affiliated Hospital of Soochow University, Suzhou 215004, Jiangsu, China.

Received: 15 July 2019 Accepted: 21 November 2019

Published online: 11 December 2019

\section{References}

1. Singh KR, Agarwal G, Nanda G, et al. Morbidity of chemotherapy administration and satisfaction in breast Cancer patients: a comparative study of totally implantable venous Access device (TIVAD) versus peripheral venous Access usage [J]. World J Surg. 2014;38(5):1084-92.

2. Minichsdorfer $C$, Füreder T, Mähr B, et al. A cross-sectional study of patients satisfaction with totally implanted Access ports [J]. Clin J Oncol Nurs. 2016; 20(2):175-80.

3. Schmidli J, Widmer MK, Basile C, et al. Clinical practice guidelines of the European Society for Vascular Surgery (ESVS) it?[J]. Eur J Vasc Endovas Surg. 2018:S1078588418302119.

4. Seo TS, Song MG, Kim JS, et al. Long-term clinical outcomes of the singleincision technique for implantation of implantable venous access ports via the axillary vein [J]. J Vasc Access. 2017;18(4):345-51.

5. Wu S, Huang J, Jiang $Z$, et al. Internal jugular vein versus subclavian vein as the percutaneous insertion site for totally implantable venous access devices: a meta-analysis of comparative studies.[J]. BMC Cancer. 2016;16(1):747.

6. Aydın T, Balaban O, Koçulu R, et al. Where is the Guidewire? Confirmation of central catheter placement in the brachiocephalic vein using Y-shape visualization by ultrasound [J]. Cureus. 2019;11(2):e4124.

7. Breschan C, Platzer M, Jost $\mathrm{R}$, et al. Consecutive, prospective case series of a new method for ultrasound-guided supraclavicular approach to the brachiocephalic vein in children [J]. Br J Anaesth. 2011;106(5):732-7.

8. Merchaoui Z, Laustenthomsen U, Pierre F, et al. Supraclavicular approach to ultrasound-guided brachiocephalic vein Cannulation in children and neonates [J]. Front Pediatr. 2017:5:211.

9. Beccaria PF, Silvetti $S$, Lembo $R$, et al. The brachiocephalic vein as a safe and viable alternative to internal jugular vein for central venous Cannulation [J]. Anesth Analg. 2018:127(1):146-50.

10. Sun $X$, Zhang Y, Yang C, et al. Ultrasound-guided totally implantable venous access device through the right innominate vein in older patients is safe and reliable [J]. Geriatr Gerontol Int. 2019;19(3):218-21.

11. Xingwei $S$, Jin $X$, Rui $X$, et al. Efficacy and safety of ultrasound-guided totally implantable venous access ports via the right innominate vein in adult patients with cancer: single-Centre experience and protocol []]. Eur J Surg Oncol. 2019:45(2):275-8.

12. Sticca RP, Dewing BD, Harris JD. Outcomes of surgical and radiologic placed implantable central venous access ports [J]. Am J Surg. 2009;198(6):829-33.

13. Goltz JP, Petritsch B, Kirchner J, et al. Percutaneous image-guided implantation of totally implantable venous access ports in the forearm or the chest? A patients' point of view [J]. Support Care Cancer. 2013;21(2): 505-10

14. Goossens GA, Stas M, JérMe M, et al. Systematic review: malfunction of totally implantable venous access devices in cancer patients [J]. Support Care Cancer. 2011;19(7):883-98.

15. Nagasawa $Y$, Shimizu T, Sonoda $H$, et al. Is catheter rupture rare after totally implantable access port implantation via the right internal jugular vein? Report of a case []]. Surg Today. 2014;44(7):1346-9.

16. Han BM, Sormaz IC, Türkay R, et al. Pinch-off syndrome, a rare complication of totally implantable venous Access device implantation: a case series and literature review [J]. Korean J Thorac Cardiovasc Surg. 2018:51(5):333-7.

17. Dauser B, Stopfer J, Ghaffari S, et al. Subclavian vein puncture vs surgical cut-down to the cephalic vein for insertion of totally implantable venous access ports [J]. Eur Surg. 2012;44(5):331-5. 
18. Klaiber U, Grummich K, Jensen K, et al. Closed cannulation of subclavian vein vs open cut- down of cephalic vein for totally implantable venous access port (TIVAP) implantation: protocol for a systematic review and proportional metaanalysis of perioperative and postoperative complications [J]. Syst Rev. 2015;4(1):53.

19. Orci LA, Meier RPH, Morel P, et al. Systematic review and meta-analysis of percutaneous subclavian vein puncture $r$, versus $\backslash$, surgical venous cutdown for the insertion of a totally implantable venous access device [J]. Br J Surg. 2014;101(2):8-16

20. Koketsu S. Outcome of cephalic vein cut-down approach: a safe and feasible approach for totally implantable venous access device placement [J]. Oncol Lett. 2010;1(6):1029-31.

21. Otsubo R, Hatachi T, Shibata K, et al. Evaluation of totally implantable central venous access devices with the cephalic vein cut-down approach: usefulness of preoperative ultrasonography [J]. J Surg Oncol. 2015;113(1): $114-9$.

22. Aytekin C, Ozyer U, Harman A, Boyvat F. Ultrasound-guided brachiocephalic vein catheterization in infants weighing less than five kilograms. J Vasc Access. 2015;16(6):512-4.

23. Thompson ME. Ultrasound-guided Cannulation of the brachiocephalic vein in infants and children is useful and stable [J]. Turk J Anaesthesiol Reanim. 2017:45(3):153-7.

24. Nardo MD, Stoppa F, Marano M, et al. Ultrasound-guided left brachiocephalic vein Cannulation in children with underlying bleeding disorders: a retrospective analysis [J]. Pediatr Crit Care Med. 2013;15(2):e44-8.

25. Voog E, Campion L, du Rusquec P, et al. Totally implantable venous access ports: a prospective long-term study of early and late complications in adult patients with cancer. Support Care Cancer [J]. 2018;26(1):81-9.

26. Wang YC, Lin PL, Chou WH, et al. Long-term outcomes of totally implantable venous access devices []]. Support Care Cancer. 2017;25(7): 2049-54.

27. Balsorano $P$, Galducci $G$, De Fanti I, et al. Fractures of totally implantable central venous ports: more than fortuity. A three-year single center experience [J]. J Vasc Access. 2014;15(5):391-5.

28. Lin CH, Wu HS, Chan DC, et al. The mechanisms of failure of totally implantable central venous access system: analysis of 73 cases with fracture of catheter [J]. Eur J Surg Oncol. 2010;36(1):1000-3.

29. Wang SC, Tsai CH, Hou CP, et al. Dislodgement of port-a catheters in pediatric oncology patients: 11 years of experience [J]. World J Surg Oncol. 2013;11(1):191.

30. Biffi R, Toro A, Pozzi S, et al. Totally implantable vascular access devices 30 years after the first procedure. What has changed and what is still unsolved?[]]. Support Care Cancer. 2014;22(6):1705-14.

31. Isidoro DC, Adriana T. Do we still need studies on the value of the TIVAD for cancer patients?[J]. World J Surg. 2014;38(8):2186.

\section{Publisher's Note}

Springer Nature remains neutral with regard to jurisdictional claims in published maps and institutional affiliations.

Ready to submit your research? Choose BMC and benefit from:

- fast, convenient online submission

- thorough peer review by experienced researchers in your field

- rapid publication on acceptance

- support for research data, including large and complex data types

- gold Open Access which fosters wider collaboration and increased citations

- maximum visibility for your research: over $100 \mathrm{M}$ website views per year

At $\mathrm{BMC}$, research is always in progress.

Learn more biomedcentral.com/submissions 